\title{
CONSTRUINDO O ESTÁGIO DE DOCÊNCIA DA PÓS-GRADUAÇÃo EM QUÍMICA
}

\author{
Judith P. A. Feitosa* \\ Departamento de Química Orgânica e Inorgânica, Universidade Federal do Ceará, CP 12200, 60455-760 Fortaleza - CE
}

Recebido em 13/11/00; aceito em 11/4/01

\begin{abstract}
DEVELOPING THE APPRENTICESHIP ON TEACHING FOR POST-GRADUATION STUDENTS IN CHEMISTRY. The teaching apprenticeship established by CAPES for post-graduation scholarship beholders has been discussed and the criterion adopted for the implementation in the post-graduation in Inorganic Chemistry Program presented. A teaching plan for the new subject is proposed, based on the experience gained through a first group. An instrument for evaluation of the student's performance has been developed and analyzed. Aspects like knowledge, clearness, enthusiasm, confidence, good manage on the audio-visual resources, class length are mentioned by degree of importance and the major difficulties faced and pointed out by the students.
\end{abstract}

Keywords: chemistry education; teaching apprenticeship; post-graduation.

\section{INTRODUÇÃO}

O Estágio de Docência na graduação para alunos da pós-graduação, instituído recentemente pela CAPES, tem despertado na comunidade acadêmica polêmica e dúvidas quanto ao seu real propósito. Na realidade, a polêmica com relação à participação de pósgraduandos no ensino de graduação é anterior à criação do Estágio.

Ela teve início quando muitas universidades brasileiras se ressentiam da falta de professores, em decorrência do crescente número de aposentadorias e da não reposição dessa força de trabalho. Foi, então, criado - a exemplo dos teaching assistants, amplamente difundidos nos Estados Unidos - o que denominamos genericamente de monitoria de pós-graduação. A polêmica girava em torno de vários aspectos. Um deles era o tipo de retribuição que se daria por esse serviço, se em créditos, se em dinheiro, considerando-se, inclusive, que bolsistas de programas como CAPES e CNPq, em princípio, não podem ter remuneração extra. Outros aspectos, de caráter mais acadêmico, referiamse à carga horária semanal, à duração da monitoria e às exigências mínimas quanto ao semestre do pós-graduando no curso que o habilitaria a ministrar disciplina na graduação.

Com relação à versão atual do Estágio de Docência, a comunidade universitária questionou a necessidade de sua obrigatoriedade para os bolsistas, aventando, entre outras possibilidades, a de prejuízos para o tempo de titulação do pós-graduando, a de o governo federal estar induzindo a utilização dos alunos como "mão-de-obra barata", em detrimento da contratação de professores, através de concursos públicos, a do pós-graduando estar servindo como força de trabalho gratuita do seu orientador.

Esta questão tornou-se mais complexa, diante da redução do tempo de bolsa/titulação para conclusão do Mestrado e Doutorado, fixados em 24 e 48 meses, respectivamente.

A muitos desses questionamentos só a própria comunidade acadêmica pode responder, através da formatação que cada Instituição de Ensino Superior (IES) dará ao programa, do tipo de implantação

*Responsável pela disciplina de Estágio de Docência no curso de pósgraduação em Química Inorgânica da UFC, semestres 2000. 1 e 2000.2. judith@dqoi.ufc.br que cada curso de pós-graduação adotará e das experiências adquiridas ao longo da sua realização.

No sentido de contribuir para o esclarecimento de alguns aspectos desse debate, será relatada aqui a experiência de aplicação do Estágio de Docência na UFC, mais particularmente, no programa de pós-graduação em Química Inorgânica.

\section{A CRIAÇÃo do ESTÁGIO DE DOCÊNCIA PELA CAPES}

A Fundação Coordenação de Aperfeiçoamento de Pessoal de Nível Superior (CAPES) tem como objetivo principal subsidiar o MEC na formulação das políticas de pós-graduação, coordenando e estimulando - mediante a concessão de bolsas de estudo, auxílios e outros mecanismos - a formação de recursos humanos altamente qualificados para a docência em grau superior, a pesquisa e o atendimento da demanda profissional dos setores públicos e privados ${ }^{1}$. Um de seus programas, o de Demanda Social (DS), tem como objetivo promover a formação de recursos humanos de alto nível necessários ao País².

Considerando ainda que o Programa DS deve contemplar aspectos que assegurem uma formação de excelência aos bolsistas, permitindo o seu aproveitamento no sistema de ensino superior brasileiro, o Presidente da CAPES, através do ofício datado de 26 de fevereiro de 1999, decidiu incluir como cláusula no convênio mantido com as IES integrantes do Programa de Demanda Social da CAPES, a exigência do estágio docente, nos cursos de graduação, para todos os bolsistas desse programa ${ }^{3}$.

Anexas ao ofício de criação do Estágio de Docência na graduação, para alunos de pós-graduação, encontravam-se as diretrizes para a sua implantação, aqui transcritas ${ }^{3}$ :

1. É parte integrante da formação de mestres e doutores.

2. Deve ser realizado sem prejuízo do tempo de titulação do bolsista.

3. Pode ser de 1(um) semestre para o bolsista do mestrado e de 2 (dois) semestres para o bolsista de doutorado.

4. Deve ser supervisionado pelo orientador do bolsista.

Em atendimento às solicitações de esclarecimento, a CAPES, através do ofício datado de 18 de maio de 2000, informou que ${ }^{4}$ :

a) O Estágio de Docência não é aplicado para os bolsistas com experiência de docência no terceiro grau de, pelo menos, 4 (quatro) semestres. 
b) A sua obrigatoriedade aplica-se a todos, independentemente de existir ou não cursos de graduação na própria instituição. Caso não haja cursos de graduação, a instituição deverá associar-se a outras IES para atender às exigências da CAPES.

\section{A IMPLANTAÇÃO NA UFC}

A solicitação inicial da CAPES instruía, também, as IES, no sentido de que, em um prazo de 6 (seis) meses, a contar de fevereiro de 1999, o Estágio de Docência fosse instituído, e as normas internas aprovadas comunicadas à CAPES. A existência de um ofício em maio de 2000, prestando esclarecimentos sobre o referido Estágio, prova que poucas instituições cumpriram o prazo estabelecido inicialmente, através do qual, no semestre 2000.1, todos os bolsistas já deveriam estar desenvolvendo as atividades de treinamento didático exigidas.

A maioria das IES regulamentou o Estágio de Docência apenas no início de 2000. No caso da UFC, foi aprovada, em 28 de fevereiro de 2000, pelo Conselho de Ensino, Pesquisa e Extensão (CEPE), resolução ${ }^{5}$ que considerava, além da exigência da CAPES, a necessidade de promover não só o envolvimento dos cursos de pós-graduação stricto sensu com a melhoria do ensino de graduação, mas também maior integração entre a graduação e a pós-graduação.

Os pontos mais relevantes dessa Resolução são ${ }^{5}$ :

1) O Estágio de Docência será desenvolvido na forma de disciplina nos cursos de pós-graduação.

2) No caso de Mestrado, a disciplina terá 2 (dois) créditos e um total de 4 (quatro) créditos para Doutorado.

3) A carga horária atribuída ao aluno será de, no máximo, 6 horas semanais.

4) O aluno de Mestrado exercerá o Estágio em 1 (um) semestre e o de Doutorado em 2 (dois), consecutivos ou não.

5) O aluno desempenhará as atividades de ensino com participação supervisionada, em uma ou mais disciplinas dos cursos de graduação, relacionadas com a estrutura curricular do curso de pós-graduação.

Em abril de 2000, como a maioria dos cursos de pós-graduação da UFC ainda não havia criado disciplina correspondente ao Estágio de Docência, a Pró-Reitoria de Pesquisa e Pós-graduação - para atender a exigência da CAPES - ofertou uma disciplina temporária, única para todos os programas (exceto o de Química Inorgânica), que foi ministrada integralmente por docentes do curso de pós-graduação em educação brasileira da própria UFC.

A disciplina, de caráter temporário, foi denominada de Estágio de Docência para alunos dos cursos e programas de pós-graduação stricto sensu e apresentava a seguinte ementa:

"Processo educativo e a didática no ensino superior. Desenvolvimento, análise e avaliação de experiência de ensino realizada, com investigação sobre aspectos do cotidiano escolar nos cursos de graduação da UFC. Sistematização da experiência de Estágio de Docência supervisionado, em forma de relatório".

\section{A PROPOSTA ADOTADA NA PÓS-GRADUAÇÃO EM QUÍMICA INORGÂNICA DA UFC}

O Curso de Pós-graduação em Química Inorgânica da UFC, no processo de criação de seu doutorado (agosto de 1999), incluiu uma disciplina para atender à exigência da CAPES, denominada Iniciação à Docência em Química Inorgânica, com 2 créditos práticos, equiivalendo a uma carga horária semanal de 4 horas de atividades durante aproximadamente 17 semanas (carga horária total de 66 horas). A disciplina é destinada a alunos de mestrado e doutorado, e tem caráter obrigatório para os bolsistas da CAPES e opcional para os demais alunos. Com a aprovação pela CAPES do programa do curso - no nível de doutorado, para início em 2000.1, a disciplina foi ofertada já naquele semestre para alunos de mestrado cuja vigência da bolsa tivesse iniciado em 1998.2.

A disciplina foi ofertada para seis alunos, com estrutura ainda em processo de construção, e ministrada por docente do próprio curso de pós-graduação, que contou com a colaboração de docente da área de educação/química.

A ementa da disciplina era inicialmente a seguinte:

"Práticas de conteúdos que possibilitem o aprimoramento da formação do aluno de mestrado e de doutorado na área de ensino em Química. O aluno deverá acompanhar as atividades didáticas de uma disciplina da graduação, sob orientação e supervisão do professor orientador".

A estrutura adotada para a disciplina contemplava os dois pressupostos ou exigências da arte de ensinar: o conhecimento e a habilidade em transmiti-lo. Segundo Loiola ${ }^{6}$, existem duas crenças equivocadas:

a) "ter talento é suficiente para ensinar o que quer que seja"; e

b) "somente o conhecimento da matéria importa".

A primeira poderia se denominar de "pedagogismo", e a segunda de "conteudismo". Pretendíamos não cometer os excessos nem de uma, nem de outra, e encontrar uma estrutura de disciplina que as harmonizasse em um todo comum.

A estrutura proposta para a disciplina, de 66 horas, foi a seguinte:

1) Seminários sobre aspectos didático-pedagógicos 22 horas

2) Observação de regência de aula 10 horas

3) Regência de aula

4) Treinamento em avaliação de aprendizagem

5) Avaliação

10 horas

Os seminários sobre aspectos didáticos foram ministrados por docente da área de Química com doutorado na área de Educação, tendo sido abordados os seguintes assuntos:

a) $\mathrm{O}$ ato de ensinar na perspectiva crítica.

b) O planejamento escolar.

c) Técnicas de grupo.

d) Utilização de multimeios.

e) Avaliação de aluno e de professor.

Na observação da regência de aula, o aluno estagiário assistia a três aulas (com duração de duas horas cada) de um professor escolhido pelo coordenador da disciplina. Ao final do período de observação, a didática adotada pelo professor era discutida. Todos os alunos assistiam aula do mesmo professor, mas em duas turmas diferentes, para que a presença de um número muito grande de observadores não perturbasse a dinâmica de classe. O professor escolhido tem comprovada experiência em sala de aula e é considerado como uma referência para o ensino da química.

A partir daí, para efetivar a regência de aula, foi apresentado para os alunos um leque de turmas de Química Geral - ou disciplinas correlatas (Química Geral I e II, específica dos cursos de Química - bacharelado e licenciatura), com os respectivos horários e os professores responsáveis. Foram indicadas para vivência do estágio as turmas ministradas para cursos de Química ou afins (Química Industrial, Farmácia), cujo professor responsável tivesse larga experiência de magistério. Dessa forma, foram excluídas as turmas sob a responsabilidade de professores substitutos, recém-ingressos na UFC.

A regência foi praticada nas turmas escolhidas por cada aluno estagiário. $\mathrm{O}$ assunto da aula foi, também, de livre escolha, a partir do conteúdo programático da disciplina. Aconselhava-se, no entan- 
to, que as escolhas recaíssem sobre tópicos diferentes. O programa da disciplina de Química Geral (cursos de Química Industrial e Farmácia) ainda é o tradicional:

1. Química: Uma Ciência Experimental.

2. Estequiometria.

3. A Estrutura dos átomos.

4. Classificação Periódica.

5. Ligações Químicas.

6. Soluções.

7. Cinética e Equilíbrio Químico.

8. Ácidos e Bases.

9. Oxidação e Redução: Células Eletrolíticas.

No caso das disciplinas introdutórias nos cursos de Química bacharelado e licenciatura (Química Geral I e II) -, o programa é basicamente o mesmo. A modificação introduzida há alguns anos é mais na profundidade em que os assuntos são tratados que no próprio conteúdo programático: acrescenta-se apenas uma unidade sobre Termodinâmica. Além disso, é maior a carga horária experimental. Química Geral tem carga horária de 6 h/semana (4 teóricas e 2 práticas) e é ministrada em 1 (um) semestre. Para os cursos de Química é ministrada em duas disciplinas, Química Geral I e Química Geral II, cada uma delas com 6 h/semana, sendo 4 teóricas e 2 práticas, para a primeira, e 2 teóricas e 4 práticas para a segunda.

Estudos recentes ${ }^{7}$ demonstraram que a disciplina Química Geral para alunos que ingressam no curso de Química deveria ser centrada em estrutura atômica e ligação química, com uma abordagem mais profunda. Segundo o autor, a forma tradicional, - conteúdo e, principalmente, abordagem, estaria desencorajando alunos para o estudo da Química e de todas as suas aplicações importantes, em vez de despertar o seu interesse.

Faria dos Santos Filho ${ }^{7}$ refere-se, no entanto, à realidade de alunos da UNICAMP, que ingressam na universidade com boa bagagem em Química, diferentemente da situação da maioria dos alunos nos cursos de Química e afins da UFC. Na UNICAMP, a relação candidato/vaga para os cursos de Química se situa na faixa de 6 a 12 (vestibulares 1999 e 2000$)^{8}$, ao passo que na UFC fica, tradicionalmente, na faixa de 2 a 4 . As deficiências desses alunos, a nosso ver, justificam manter o conteúdo programático mais abrangente e mais tradicional. É evidente que não só a manutenção de conteúdo é suficiente: formas alternativas têm sido buscadas para motivar os alunos para o ensino-aprendizagem da Química ${ }^{9}$.

Voltemos ao relato da experiência com a disciplina Iniciação à Docência em Química Inorgânica na UFC. Com base no conteúdo programático adotado, foram escolhidos os seguintes temas pelos alunos estagiários: Ligações Químicas (2 alunos); Ácidos e Bases (1 aluno); Termodinâmica (1 aluno) e Oxidação e Redução (2 alunos). Para cada uma dessas unidades, estavam previstas de três a quatro aulas de duas horas. O estagiário deveria, também, ministrar uma aula de laboratório (2 horas) e corrigir os relatórios dos alunos, de preferência sobre o mesmo assunto da aula teórica escolhida por ele.

Antes de assumir a regência de turma no tema escolhido, cada aluno estagiário ministrava aulas para os colegas pós-graduandos do curso de Iniciação à Docência, e essa atividade era comentada tanto pelo docente responsável por essa disciplina quanto por seus colegas com sugestões de melhorias relativas a aspectos de conteúdo e de forma. O aluno estagiário devia fazer também uma auto-avaliação, que costumava ser tímida no início, mas que, ao longo do curso, tornava-se mais consciente e realista.

Depois dessa vivência, os alunos exerciam a regência de aula, que era observada pelo coordenador da disciplina. Novamente, sugestões eram dadas ao aluno para aprimorar sua aula, uma vez que agora havia uma elemento novo, a presença de uma turma real de graduação. Além da regência de aula, coube também ao estagiário a elaboração de lista de exercício e de questões para a avaliação.

$\mathrm{O}$ treinamento para realizar a avaliação foi efetuado em duas etapas e com base na atividade laboratorial. A primeira delas constava do treinamento na correção dos relatórios. Um lote de sete relatórios de alunos de uma prática de Química Geral (no caso, Estequiometria) foi distribuído para cada estagiário: cinco deles eram relatórios originais e dois eram cópias de relatórios distribuídos para outros estagiários. A instrução e os critérios para a correção foram discutidos e o resultado das notas dos alunos foram analisados. Como em cada lote de relatórios corrigidos havia dois em comum com outros lotes, as notas atribuídas foram comparadas, a fim de verificarse o grau de subjetividade e o rigor relativo na correção.

Observou-se variação de até 3 pontos, em escala de 0 a 10 , entre notas auferidas por diferentes estagiários para um mesmo relatório. A variação máxima entre as notas atribuídas a um mesmo relatório foi de $40 \%$ e a mínima de $1 \%$. Em 50\% dos relatórios a variação de nota foi menor que $10 \%$. Em $30 \%$ dos casos as notas variaram de 10 a $30 \%$. Variação acima de $30 \%$ foi verificada em $20 \%$ dos relatórios. Os casos em que a discrepância foi muito alta foram rediscutidos, no intuito de verificar o que causava as diferenças na avaliação. Em algumas situações, a partir dos argumentos levantados pelo grupo, os próprios estagiários fizeram ajustes nas notas que haviam atribuído. A maior diferença entre as notas baixou de 3 para 0,8 pontos, que corresponde a $10 \%$ de variação.

Conclui-se, portanto, que, mesmo com os critérios de correção definidos, a subjetividade ainda é um parâmetro essencial na avaliação, especificamente em casos em que - como o que ocorre com relatórios - não existe um delineamento muito claro do que seja considerado $100 \%$ correto. A avaliação coletiva está sendo duplamente importante, pois possibilita comparação dos critérios e do rigor adotados pelo estagiário com os dos colegas e do professor.

A avaliação dos estagiários foi feita ao longo do semestre, com base em sua participação nas atividades previstas e em seu desempenho na regência de aula e na prova didática. No caso da regência de aula, o professor responsável pela disciplina da graduação também foi ouvido. A prova didática foi a simulação de um concurso para professor substituto. Foram adotadas as normas da UFC, especificamente no que se refere ao Art. $5^{\circ}$ da Portaria No 1007 do Reitor da UFC, aqui transcrito ${ }^{10}$ :

"A prova didática, constante de aula com duração de 50 (cinqüenta) minutos, sobre tema ou temas sorteados para cada concorrente, com 24 (vinte e quatro) horas de antecedência, observados os programas aprovados pelo departamentos interessado, objetivará aferir a capacidade do candidato relativamente à utilização dos recursos de comunicação e técnicas de ensino, bem como avaliar seu domínio do assunto abordado e suas condições pessoais para desempenho da atividade docente".

Os pontos a serem sorteados correspondem aos itens 2 a 9 do programa da disciplina Química Geral, especificado anteriormente. Como todos os alunos estagiários participariam da avaliação dos colegas optou-se, diferentemente de um concurso real, em não repetir os pontos sorteados. Da Banca Examinadora faziam parte, também, o orientador do estagiário e o coordenador da disciplina de estágio.

Para a avaliação dessa aula, e no intuito de possibilitar uma maior uniformidade no processo de avaliação, foi elaborada, em conjunto com os alunos, uma Ficha de Avaliação (Quadro 1) em que eram discriminados os itens considerados mais significativos como indicadores de desempenho.

A pergunta final tinha a finalidade de avaliar a pertinência dos itens utilizados na avaliação, sua importância relativa e a correlação entre eles, na tentativa de estabelecer um perfil ideal de professor e de conhecer as dificuldades enfrentadas pelos estagiários para alcançar este perfil. 
Quadro 1. Ficha de Avaliação para a prova didática dos alunos do Estágio de Iniciação à Docência da UFC, semestre 2000.1 .

\begin{tabular}{|cl|c|c|c|c|c|}
\hline ITEM & INDICADOR DE DESEMPENHO & INS & REG & BOM & MBOM & EXC \\
\hline 1 & CONHECIMENTO DO TEMA (peso 3) & & & & & \\
\hline 2 & CLAREZA NA EXPOSIÇÃO & & & & & \\
\hline 3 & SEGURANÇA NA EXPOSIÇÃO & & & & & \\
\hline 4 & ENTUSIASMO NA EXPOSIÇÃO & & & & & \\
\hline 5 & IMPORTÂNCIA DOS TÓPICOS ABORDADOS & & & & \\
\hline 6 & DISTRIBUIÇÃO DOS TÓPICOS NO TEMPO & & & & \\
\hline 7 & DURAÇÃO DA AULA & & & & & \\
\hline 8 & UTILIZAÇÃO DOS RECURSOS (QUADRO, RETROPROJETOR, ETC) & & & & & \\
\hline
\end{tabular}

Qual seria o seu conceito global independentemente da análise acima?

\section{AVALIANDO A AVALIAÇÃo}

Para avaliar o próprio instrumento de avaliação, inicialmente buscou-se comparar o Conceito Global auferido independentemente da pontuação em cada item com aquele obtido pela média dos itens.

Foram feitas simulações considerando pesos diferentes para o item 1, Conhecimento do Tema. Com peso 1, 10 avaliações globais, de um total de 31 , não coincidiram com o conceito obtido pela média dos itens. Com peso 2, 4 não coincidiram; e com o peso 3, 8 . Contata-se, assim, que, apesar de ter sido indicado peso 3 para o item Conhecimento do Tema, os avaliadores na realidade consideraram-no com peso 2 . Utilizando esse peso, apenas $13 \%$ das avaliações globais não correspondiam ao somatório das avaliações por cada item. Conclui-se, portanto, que a Ficha de Avaliação utilizada contempla os aspectos fundamentais e é adequada ao que se propõe: avaliação de uma aula de concurso.

Calculou-se, também, a percentagem de coincidência entre o conceito do item com o Conceito Global, na tentativa de verificar o grau de importância conferido a cada item. Quanto maior o grau de coincidência, maior a importância conferida. Observou-se que os indicadores de desempenho podem ser agrupados em 3 classes em função de sua importância.

GRUPO I: Aspectos determinantes do Conceito Global, cuja associação média entre o conceito do item e o conceito global é de $60 \%$.

1. Conhecimento do tema

2. Clareza

3. Segurança

4. Entusiasmo

GRUPO II. Aspectos de importância intermediária, com 50\% de associação.

5. Importância dos tópicos abordados

6. Distribuição dos tópicos no tempo

GRUPO III. Aspectos menos relevantes, com associação média de $30 \%$.

7. Duração da aula

8. Utilização dos recursos audiovisuais

A outra forma de aquilatar a relevância de cada item foi através daquelas situações em que o Conceito Global não coincidia com a média dos itens. Verificava-se, então, que itens foram determinantes na escolha do Conceito Global. O grau de coincidência do conceito do item com o do Conceito Global indica quão determinante ele foi na escolha do Conceito Global:

1. Conhecimento do tema $60 \%$

2. Clareza $60 \%$

3. Segurança $50 \%$

4. Entusiasmo $40 \%$

5. Importância dos tópicos abordados $35 \%$

6. Distribuição dos tópicos no tempo $35 \%$

7. Duração da aula $20 \%$

8. Utilização dos recursos (quadro, retroprojetor, etc.) $10 \%$

Observa-se que as duas verificações apontam para a mesma ordem de importância dos itens, que, coincidentemente, corresponde à ordem de aparecimento na Ficha de Avaliação.

A associação entre cada par de indicadores de desempenho foi determinada através da coincidência entre os conceitos a eles atribuídos. Todas as combinações possíveis foram testadas, mesmo aquelas em que as relações eram improváveis. Considerou-se como associados aqueles indicadores de desempenho com ocorrência coincidente de, no mínimo, $50 \%$. Com base nesse pressuposto foi construído o Diagrama 1. Como Clareza e Conhecimento do Tema foram anteriormente determinados como os aspectos mais importantes foi feito um destaque especial para eles.

Pelo Diagrama 1, a Clareza, a Segurança e o Conhecimento parecem constituir a espinha dorsal, a partir da qual são construídas as interligações secundárias. Reforça-se com isso a tese de Loiola ${ }^{6}$ : nada de "pedagogismo", nem de "conteudismo" isolados. A Clareza - reflexo da habilidade de ensinar - e o Conhecimento - que corresponde ao conteúdo -, são imbricados de tal forma que é impossível a existência de um sem a coexistência do outro.

Quanto mais Clareza tiver a exposição, mais Entusiasmo e Segurança o docente transmitirá. É a nossa autoconfiança alimentando o processo. Pressupõe-se, também, que em uma exposição clara, os recursos audiovisuais estejam sendo utilizados adequadamente, como mostra o Diagrama 1.

O Conhecimento confere ao docente a Segurança, que, por sua vez, realimenta a Clareza. O domínio do assunto possibilita, também, a escolha adequada dos tópicos mais importantes a serem abordados no curto espaço de uma aula de concurso (50 minutos). A escolha adequada dos tópicos essenciais necessita, além do conhecimento em si, uma certa dose de maturidade. Provavelmente por isso a associação entre eles seja menor do que as demais (50\%, enquanto nas outras é de 60\%). 


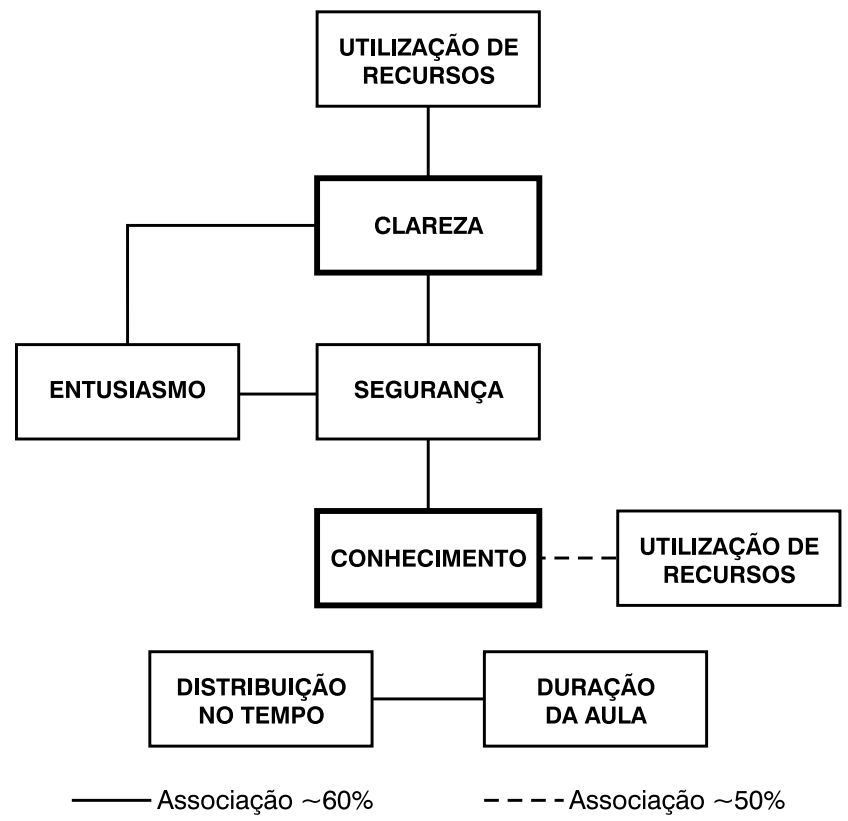

Diagrama 1. Associação observadas entre os vários indicadores de desempenho utilizados para avaliar uma aula tipo concurso.

Verifica-se, também, a partir dos dados, que os dois indicadores que se referem a tempo (Duração da aula e a Distribuição do tópicos no tempo), apesar de interligados, não apresentaram associação com os demais.

Outro aspecto pesquisado foi relativo às maiores dificuldades enfrentadas pelos alunos. Os três indicadores de mais baixo conceito obtidos por cada um deles foram computados e, através das maiores incidências, constatou-se que as dificuldades enfrentadas foram, em ordem decrescente:

$1^{\circ}$ ) Distribuição dos tópicos no tempo e Duração da aula

$2^{\circ}$ ) Entusiasmo, Clareza e Importância dos tópicos

$3^{\circ}$ ) Segurança e Utilização de Recursos.

$\mathrm{O}$ aspecto Conhecimento do Tema não se apresentou como dificuldade, uma vez que, para nenhum aluno, ele foi avaliado como um dos três indicadores de mais baixo desempenho. $\mathrm{O}$ fato de terem boa base científica, como alunos de pós-graduação que são, certamente lhes confere o conhecimento suficiente para ministrar uma aula de Química Geral sem problema de conteúdo.

Por outro lado, $50 \%$ dos alunos ministraram aula de aproximadamente 30 minutos, o que reflete sua dificuldade em controle do tempo.

\section{RELENDO O PROCESSO... DO CONCEBIDO AO VIVIDO}

Por ocasião do Seminário Final, foi feita uma avaliação da disciplina. Na opinião dos alunos, ela foi muito útil. Reconheceram que apesar de terem que proferir, ao longo do curso de pós-graduação, vários seminários, essa atividade não os preparava para a sala de aula.

Discutiu-se, também, o distanciamento entre o que se havia programado para cada etapa e o que de fato havia ocorrido no desenvolvimento das atividades, e algumas sugestões foram dadas para melhorar o processo de construção da disciplina:

a) tornar a parte didática mais sucinta;

b) fazer uma reunião inicial com a turma do estágio e os professores responsáveis pelas disciplinas da graduação nas quais os alunos farão o treinamento didático;

c) fazer a observação da regência de aula na mesma turma em que ministrarão as aulas, ou seja, cada aluno estagiário deve- rá observar um professor diferente - o responsável pela disciplina de graduação na qual ele fará sua prática docente;

d) cada aluno deve observar, também, a turma em uma unidade que preceda aquela que ele vai ministrar, com a finalidade não só de verificar características da turma (grau de conhecimento, receptividade, interesse, etc.), os conhecimentos que já estão sendo transmitidos, mas também de estabelecer familiaridade com os seus futuros alunos;

e) manter a preparação para a regência da turma, ministrando a aula para a turma do próprio Estágio de Docência;

f) manter uma unidade para a regência de aula, com duas a três aulas teóricas, uma de exercício e uma de laboratório;

g) designar cada estagiário como observador da regência de aula de outro colega;

h) manter correção coletiva dos relatórios;

i) introduzir correção coletiva de prova;

j) manter avaliação final através de simulação de aula de concurso.

Com base nas sugestões e críticas dos alunos e dos professores e com a experiência adquirida com essa primeira turma, foi proposto um Plano de Ensino da disciplina, que poderá ser novamente modificado e aprimorado. Afinal, segundo Brandão $0^{11}$, a atividade didática é um processo constante de construção/desconstrução/reconstrução.

O Plano de Ensino da disciplina Iniciação à Docência em Química I é atualmente o seguinte:

1. EMENTA: Estudo das diferentes técnicas de ensino e sua aplicação à transmissão do conhecimento em Química Geral na graduação

2. OBJETIVO GERAL: Fornecer aos pós-graduandos formação didática e treinamento em atividade de ensino de graduação, qualificando-os para o magistério superior e promovendo maior integração entre a Graduação e a Pós-Graduação.

3. PROGRAMAÇÃO

ATIVIDADE DURAÇÂO

(horas/semestre)

- Seminários introdutórios sobre temas 16 relativos à Didática, Planejamento, Avaliação, Currículo, etc;

- Análise da disciplina Química Geral na 02 estrutura curricular

- Elaboração dos planos de aula e programas das disciplinas de Química Geral

- Observação de regências, em sala de aula teórica e em laboratório, de professores de Química Geral

- Aulas teóricas expositivas dos discentes para a turma de Iniciação à Docência, seguidas de discussão entre alunos e professor

- Vivência em regências em sala de aula e em laboratório de Química Geral supervisionada pelo professor responsável pela disciplina da graduação e pelo professor da disciplina de Iniciação à Docência

- Treinamento em avaliação da aprendizagem (relatórios e provas) através de correção de relatórios de aulas práticas e provas, seguida de discussão entre alunos e professor sobre os critérios utilizados

- Aula teórica expositiva - tipo concurso ministrada pelos discentes para uma Banca Examinadora, incluindo o responsável pela disciplina e o orientador do aluno

- Seminário final 
4. BIBLIOGRAFIA RECOMENDADA

- GERAL: Moreira ${ }^{12}$, Davis ${ }^{13}$

- ESPECÍFICA: Kotz e Treichel ${ }^{14}$, Masterton e Slowinski ${ }^{15}$, Chang $^{16}$.

No semestre atual, 2000.2, a disciplina Iniciação à Docência em Química Inorgânica I está sendo ministrada para sete alunos, seguindo o Plano de Ensino proposto. Conta com a colaboração de quatro docentes da Faculdade de Educação, para os Seminários Introdutórios, e cinco do Departamento de Química Orgânica e Inorgânica, como professores das turmas de Química Geral na graduação.

A disciplina Iniciação à Docência em Química Inorgânica II, criada para os alunos do doutorado, com 2 créditos práticos e $4 \mathrm{~h} /$ semana de atividade, apresenta estrutura semelhante à da disciplina I, com as seguintes diferenças:

1) Os Seminários Introdutórios são dispensados.

2) Inclui turma de Química Inorgânica como campo de estágio.

3) Prevê mais tempo de regência em sala de aula.

4) Prevê a elaboração de roteiro de prática.

\section{ENFIM, UMA CONCLUSÃO PROVISÓRIA ESCRITA COM OS ATORES DA AÇÃO DOCENTE JUNTO À GRADUAÇÃO}

Várias conclusões podem ser oriundas desse trabalho e das discussões em torno do tema:

1) Considerando a opinião dos alunos que cursaram a disciplina e a procura para a segunda turma, mesmo de alunos não bolsistas da CAPES - para os quais a disciplina não é obrigatória - pode-se afirmar que o Estágio de Docência é muito útil para a formação do futuro professor e sua importância transcende à obrigatoriedade imposta pela CAPES.

2) A implantação do estágio através de disciplinas (1 para Mestrado e 2 para doutorado) parece adequada.

3) A programação proposta, que abrange aspectos didáticos teóricos e práticos, é essencial para uma boa formação do pósgraduando.

4) As atividades previstas na disciplina impedem a utilização dos pós-graduandos como "mão-de-obra barata", ou como substitutos dos professores ou orientadores na sala de aula.

5) A supervisão do estágio não pode ser feita pelo professor orientador, como proposto pela CAPES, pois ele nem sempre ministra disciplinas de graduação, ou quando as ministra não necessariamente é a disciplina mais apropriada.

6) A participação do orientador é possível e salutar, se mantida no processo de avaliação final do estagiário.

7) O Instrumento de Avaliação proposto é adequado à sua finalidade.

8) Os aspectos do Instrumento de Avaliação relativos à Clareza e ao Conhecimento do Tema são os essenciais para um bom desempenho didático.
9) Todos os aspectos analisados para aferir a qualidade da aula ministrada pelos alunos são interligados entre si, exceto aqueles temporais (Duração da aula e Distribuição dos tópicos no tempo).

10) As maiores dificuldades enfrentadas pelos alunos são relativas à duração da aula e ao tempo a ser gasto com cada tópico do assunto a ser ministrado.

11) Reafirma-se a importância da aproximação/participação de pós-graduandos no ensino de graduação.

12) A arte de ensinar é processo dinâmico, que precisa ser encarada como atividade de ensino e de pesquisa, em um contínuo processo de construção/desconstrução/reconstrução.

\section{AGRADECIMENTOS}

Agradeço às professoras Claudia Cristina B. e S. Carneiro, Ana Maria I. Dias e Maria de Lourdes P. Brandão e aos professores Luiz B. Albuquerque e Francisco A. Loiola, da área de educação da UFC, que ministraram os Seminários Introdutórios. Às Profas. Maria de Lourdes Brandão e Vera Cristina R. Feitosa (UFRJ) agradeço, também, pelas sugestões e leitura crítica deste trabalho. Aos alunos do curso de pós-graduação em Química Inorgânica que participaram da turma 2000.1 e que estão participando da turma 2000.2, e aos professores das disciplinas de graduação em Química, parceiros na construção desta proposta, meu agradecimento especial.

\section{REFERÊNCIAS}

1. www.capes.gov.br/oqueecapes/apresentação.

2. www.capes.gov.br/bolsas/DS.

3. Ofício 028/99/PR/CAPES, do Presidente da CAPES, Abílio Afonso Baeta Neves, datado de 26 de fevereiro de 1999.

4. Ofício CDS/CAPES/CIRC/N020/00, da Coordenadora de Desenvolvimento Setorial da CAPES, Zena Martins, datado de 18 de maio de 2000.

5. Resolução ${ }^{\circ}$ 03/CEPE/UFC, de 28 de fevereiro de 2000, do Magnífico Reitor da Universidade Federal do Ceará.

6. Loiola, F. A.; Concepções sobre Ensino e Aprendizagem na Universidade, mimeo, Canadá, 1998

7. Faria dos Santos Filho, P.; Quim. Nova 2000, 23, 699.

8. www.convest.unicamp.br

9. Rodrigues, J. F.; Jucá, M. E. W.; Quim. Nova 1993, 16, 60

10. Portaria $\mathrm{n}^{\circ} 1007$, de 19 de julho de 1991, do Magnífico Reitor da Universidade Federal do Ceará.

11. Brandão, M. L. P.; Demarcando o Cenário do Estágio de Docência no Cotidiano Universitário, mimeo, Fortaleza

12. Moreira, D. A. (org); Didática do Ensino Superior: Técnica e Tendências, Editora Pioneira, São Paulo, 1997

13. Davis, B. G.; Tools for Teaching, Jossey-Bass Publishers, San Francisco, 1993.

14. Kotz, J. C.; Treichel, P. Jr.; Química e Reações Químicas, 3ª ed., Vol 1 e 2, Livros Técnicos e Científicos Editora S.A., Rio de Janeiro, 1998.

15. Masterton. W. L.; Slowinski J.; Princípios de Química, 6 ${ }^{\mathbf{a}}$ ed., Ed. Guanabara, Rio de Janeiro, 1990.

16. Chang, R.; Química, 5ª ed., Mc Graw Hill, Portugal, 1998. 